\title{
Participação política no Brasil no século XXI: mudanças e continuidades
}

\author{
Political participation in Brazil in the $21^{\text {st }}$ century: changes and continuities
}

\begin{abstract}
Henrique Carlos de Oliveira de Castro
Professor do Centro de Pesquisa e Pós-graduação sobre as Américas - CEPPAC, Universidade de Brasília - UnB e-mail: hcocastro@gmail.com
\end{abstract}

\section{Fernanda Teixeira Reis}

Mestre em Ciências Sociais, Centro de Pesquisa e Pós-graduação sobre as Américas - CEPPAC, Universidade de Brasília - UnB e-mail: teixeira.f@gmail.com
Recebido: 03/09/2012

Aceito: 30/10/2012
RESUMO $\mathrm{O}$ artigo objetiva avaliar a relação entre as mudanças ocorridas nos canais de participação política dos brasileiros nos últimos 15 anos e a alegada apatia política nacional. A análise pretende elevar a mera discussão sobre correntes teórico-metodológicas dentro do estudo da participação política e cultura política participativa através do exame de como os indivíduos se orientam e agem dentro da arena estatal como um fator explicativo das dinâmicas sociais. Para tal, utilizou-se da análise de dados empíricos obtidos na pesquisa quantitativa sobre Cultura Política World Values Survey (WVS). Primeiramente, identificou-se os canais mais utilizados à participação política dos brasileiros buscando verificar se há ou não uma tendência à apatia, bem como as mudanças na participação política no Brasil nos últimos 15 anos. Posteriormente, avaliou-se a existência de um padrão semelhante na participação política em outros dois países selecionados - Estados Unidos e França - através de um estudo comparativo. Por fim, conclui-se que houve grandes mudanças nos canais participativos dos brasileiros nestes 15 anos: há uma tendência dos cidadãos participarem mais de instituições não ligadas à sociedade política. $\mathrm{O}$ brasileiro não é apático politicamente, e sim os canais governamentais não oferecem atrativos a sua participação, seguindo a mesma tendência nos dois países em questão.

PALAVRas-Chave Participação política; Cultura política; World Values Survey; Política comparada.

ABSTRACT This article claims to analyze an association between the changes in the Brazilian political participation channels in the last 15 years and the supposed national political apathy. The motivation is to understand how individuals get oriented and act within the political arena as a explanatory factor of the social dynamics. Using data from the World Values Survey (WVS) we verify that a big change has occurred in the Brazilian channels for political participation: there is a progressive tendency in the participation of citizens in the politics throughout non formal political institutions. Using comparative studies we demonstrate that Brazilian political participation follows the results found in two others nations: USA and France. There's no political apathy in Brazil but rather a lack of attractiveness in the government channels for citizens participation, following the same tendency found in the two other states analysed.

KEYWORDS Political participation; Political culture; World Values Survey; Comparative studies. 


\section{Introdução}

$\mathrm{O}$ senso comum das ciências sociais observa um alto desengajamento cívico no cenário político da América Latina. Para tal visão, o quadro político latino-americano é bastante desestimulante a uma cultura política participativa. Cidadãos parecem mais desconfiados e decepcionados com procedimentos formais de participação, como eleições e filiações em partidos políticos.

Sob este ponto de vista, o Brasil faz parte deste quadro latino-americano. Suas instituições políticas são consideradas ineficazes, corruptas e assistencialistas, o que propicia a emergência de canais de participação não relacionados à sociedade política como formas de transmissão de demandas. Indivíduos dentro desta realidade têm crescentemente se voltado à participação em grupos considerados informais e à margem das organizações convencionais (Baquero, 2003: 104). Esse tipo de comportamento vem se institucionalizando e atuando de forma cada vez mais permanente. Assim sendo, canais participativos até então avaliados como não formais e não institucionalizados necessitam ser estudados como forma legítima de participação política. As possíveis mudanças ocorridas nos canais participativos de brasileiros na última década confirmariam essa tendência. No entanto, o desengajamento cívico à participação política formal não é um processo exclusivo da América latina, em especial do Brasil. Desta forma, faz-se vital a análise comparada da participação política brasileira com outros países. O trabalho realizará a comparação com dados referentes aos Estados Unidos e à França.

A análise realizada enfocou como os indivíduos destes países agem baseados nas suas crenças e percepções. Ela partirá da pergunta geral: a participação política do brasileiro confirma a crença da postura apática do cidadão na arena política? Para tratar de forma mais apropriada a questão da apatia, algumas interrogações mais específicas se tornam pertinentes. Qual o interesse dos cidadãos pela política? Qual a importância atribuída às instituições sociais, em especial à política? Qual a importância deles serem governados por um sistema democrático? Qual a importância da participação política dos cidadãos? Esses cidadãos pertencem e participam de instituições ligadas ao aparato formal, como também das não formais? E por fim, eles tendem a confiar nestas instituições?

A participação política será medida através da ação dos indivíduos. Serão analisadas variáveis referentes ao pertencimento e a participação em instituições sociais e políticas ligadas ao aparato estatal, como também instituições não relacionadas à sociedade política. São exemplos destas instituições: sindicatos, partidos políticos, associação religiosas e humanitárias, associações profissionais, dentre outras. A confiança do cidadão nestas instituições também será examinada. Por fim, serão analisadas as formas de atuação política dos indivíduos dos três países selecionados. As variáveis referentes à como eles participam são: assinar um abaixo-assinado, participar de boicotes e participar manifestações pacíficas.

\section{Metodologia}

Não se realizou levantamento de dados específicos para este trabalho. Os dados foram obtidos da pesquisa mundial World Values Survey (WVS). O WVS é uma pesquisa quantitativa sobre Cultura Política de propriedade da Universidade de Michigan e que tem como coordenador principal o professor Ronald Inglehart. No Brasil, a pesquisa é coordenada pelo professor da Universidade de Brasília Henrique Carlos de Oliveira de Castro. A pesquisa é realizada em cerca de 80 países e suas perguntas estão relacionadas a valores socioculturais, morais, religiosos e políticos destes países. Foi estabelecido um período de cinco anos para a reaplicação do questionário. Em 1990 é feita a primeira aplicação do questionário no Brasil. Em 1995 e 2005, o questionário é reaplicado no Brasil.

OWVS será primordialmente utilizado por possuir questões específicas sobre cultura política e sobre o tema de participação política, possibilitando uma observação mais apurada da relação que se pretende estudar. Para tal, serão analisadas variáveis referentes à importância e ao interesse pela política na vida dos indivíduos. A importância da democracia e a percepção de um governo democrático também serão analisadas. Foram estudadas as ondas brasileiras de 1990 e de 2005, como também as norte-americanas e francesas de 2005. O questionário de 1990 continha 237 variáveis e foram realizadas 1782 entrevistas no Brasil. Em 2005 foram modificadas e acrescentadas novas perguntas ao questionário, passando ele a possuir 259 variáveis. Nesta onda, foram realizadas 1149 entrevistas no Brasil, 1001 na França e 1249 no EUA.

\section{Participação Política e Cultura Política}

A onda de reivindicações pela ampliação da arena política para maior participação e implementação de direitos reais, inicialmente pleiteados por movimentos de estudantes universitários e alguns grupos sociais mais pró-ativos no final da década de 60 , desloca o termo participação política ao vocábulo popular 
(Pateman, 1992: 9). A ampla utilização deste termo pela mídia também influenciou na sua popularização.

Os diferentes desenhos de participação política entre distintos países adotantes de um sistema político democrático são reflexos dos díspares contextos sociais, históricos e culturais entre estes países. A participação política é variável dependente de diferentes contextos institucionais, de mudanças populacionais e da cultura política. Uma cultura política pode determinar uma maior estrutura e demanda por participação política. Dahl (2005) demonstra no seu Poliarquia o crescimento de inúmeros sistemas democráticos no contexto mundial, no entanto cada país adotante deste sistema abraça distintos elementos institucionais, como por exemplo, diferentes canais de participação política, distintos mecanismos de competição entre as muitas forças políticas, diferentes formas de estimular a participação política ao cidadão. Deste modo, a análise da evolução da participação dos cidadãos de uma nação é um indicador da relação entre a cultura política desta nação e suas instituições políticas. (Kligemann e Fuchs, 1995: 30).

Por sua vez, a teoria do desenvolvimento humano propõe uma associação entre valores pós-materialistas e uma atitude cidadã mais participativa (Inglehart, 1990, 1999, 2001; Inglehart e Welzel, 2005). Defende-se uma alteração gradual nas prioridades valorativas dos indivíduos em nível mundial: há uma mudança no conjunto de valores humanos em direção a uma postura pós-materialista. Essa mudança é associada principalmente ao desenvolvimento econômico das ultimas décadas experimentado, especialmente, pelas sociedades industriais avançadas. A adoção de valores pós-materialistas teriam consequências positivas aos processos democratizantes, em especial à participação política, pois, uma vez superados os limites da sobrevivência econômica e material, os indivíduos estariam mais interessados em questões relacionadas à sua auto-expressão, o que resulta maior intervenção societária na política (Ribeiro e Borba, 2010). Por outro lado, atitudes pós-materialistas também representam uma postura mais crítica em relação ao funcionamento das instituições políticas da democracia representativa, primordialmente, aos instrumentos formais e tradicionais de representação. $\mathrm{O}$ que não representa um quadro de apatia política, e sim, o fortalecimento de novos canais de participação, em oposição ao aparato institucional e a antiga elite política estabelecida (Norris, 2002).

No entanto, abordar o tema participação política é fazer quase que instantaneamente a sua ligação com a participação eleitoral. A grande maioria da população acredita que sua participação na arena política se dá unicamente através do ato do voto. Essa associação é explicada pela recente inserção das massas no sistema político: o ato eleitoral foi o primeiro amplo canal de participação política direta. A inserção do cidadão na arena de decisão se deu através do estabelecimento de normas constitucionais e de um sistema eleitoral que refletiram na criação de um canal que previa a participação de todos os então cidadãos. As eleições nacionais são o grande símbolo de legitimidade democrática do Estado-nação, como também é a grande fonte de observação da estabilidade democrática de um dado país. (Kligemann e Fuchs, 1995: 28) No entanto, o sufrágio universal é uma instituição extremamente nova: muitos países que consideram possuir um sistema político democrático representativo estável só o adotam em meados do século XX. O EUA e o Canadá, países ocidentais considerados democraticamente estáveis, só adotam o sufrágio universal em 1965 em 1970, respectivamente (Chang, 2004: 130).

Apesar da teoria política contemporânea privilegiar a participação política ligada primordialmente às atividades instrumentais do voto, a expressão "participação política" nos remete a uma série de ações não somente ligadas ao ato do voto. Estas ações podem ser formalizadas e inseridas em contextos institucionais do Estado, como também informais, e até não pacíficas. Para Lúcia Avelar, as atividades ligadas à participação política:

\begin{abstract}
Vão desde as mais simples, como conversas com amigos e familiares sobre os acontecimentos políticos locais, nacionais e internacionais, até as mais complexas, como fazer parte de governos, mobilizar pessoas para protestar contra autoridades políticas, associar-se em grupos e movimentos para reivindicar direitos, envolver-se nas atividades da política eleitoral, votar, candidatar-se, pressionar autoridades para mudanças nas regras constitucionais, para favorecer grupos de interesses dos mais diversos, e mais uma plêiade de atividades que circundam o universo da vida política [...] (Avelar, 2007: 223).
\end{abstract}

Esta autora defende que participar politicamente é: "[...]tomar parte em, compartilhar, associar-se pelo sentimento ou pensamento [...]" (Avelar, 2007: 225). Seguindo este pensamento, pode-se concluir que a participação política pode ser direta ou indireta: por participação direta temos o indivíduo agindo, informando, reivindicando; já a participação indireta é fazer parte, legitimar tal ato ou associação.

\section{A Participação Política do Brasileiro}

Este bloco se analisa a evolução da participação política na Brasil nos últimos 15 anos: entre 1990 e 2005. O marco teórico foi determinado baseando-se no processo de redemocratização no Brasil. Esta fase 
se iniciou em 1985, através da eleição indireta de Tancredo Neves à Presidência da República. Em 1988 é promulgada a Constituição Federal vigente, e assim reinicia no Brasil o ciclo constitucional. Em 1989, ocorrem eleições diretas a Presidente da República, após quase 30 anos de eleições indiretas. Superadas crises econômicas - governo Sarney e Fernando Henrique Cardoso - e crises políticas - governo Fernando Collor de Melo e primeiro governo Lula - o país supostamente encontra-se num momento de maior consolidação e amadurecimento democrático desde 2005. Neste período também se constatou a ampliação dos direitos dos cidadãos e da participação política dos cidadãos. Esta ampliação se deu não só através do estabelecimento do voto direto à Presidente da República como também através de formas diretas formais, como mecanismo constitucionais de democracia direta: plebiscito, referendo e ação popular.

Desta maneira, a análise dos dados do WVS enfocará as seguintes variáveis: importância e interesse dos cidadãos pela política; importância da democracia e percepção dos indivíduos em relação a um governo democrático; pertencimento e participação em instituições sociais; e confiança do cidadão nestas instituições. Serão avaliados os dados referentes aos surveys aplicados nos anos 1990 e 2006.

A primeira análise enfocará os dados referentes ao interesse do cidadão pela política. $\mathrm{O}$ brasileiro afirma-se interessado por política, e lhe atribui importância na sua vida. A Tabela 1 e a Figura 1 indicam que o interesse pela política do brasileiro

Tabela 1. Interesse pela política, Brasil, 1990/2005.

\begin{tabular}{|c|c|c|c|c|c|c|}
\hline Onda & & & Freqüência & Percentual & Porcentagem válida & Percentual acumulado \\
\hline \multirow[t]{6}{*}{1990} & Válido & Muito interessado & 227 & 13,0 & 13,0 & 13,0 \\
\hline & & Um pouco interessado & 573 & 32,8 & 32,9 & 46,0 \\
\hline & & Não muito interessado & 305 & 17,5 & 17,6 & 63,5 \\
\hline & & Não sou interessado & 635 & 36,3 & 36,5 & 100,0 \\
\hline & & Total & 1739 & 99,6 & 100,0 & \\
\hline & Inválido & Não se aplica & 8 & 0,4 & & \\
\hline \multirow[t]{6}{*}{2005} & Válido & Muito interessado & 89 & 8,9 & 8,9 & 8,9 \\
\hline & & Um pouco interessado & 280 & 28,0 & 28,0 & 36,9 \\
\hline & & Não muito interessado & 317 & 31,7 & 31,7 & 68,6 \\
\hline & & Não sou interessado & 314 & 31,4 & 31,4 & 100,0 \\
\hline & & Total & 1000 & 99,9 & 100,0 & \\
\hline & Inválido & Não se aplica & 1 & 0,1 & & \\
\hline
\end{tabular}

Fonte: Pesquisa World Values Survey.

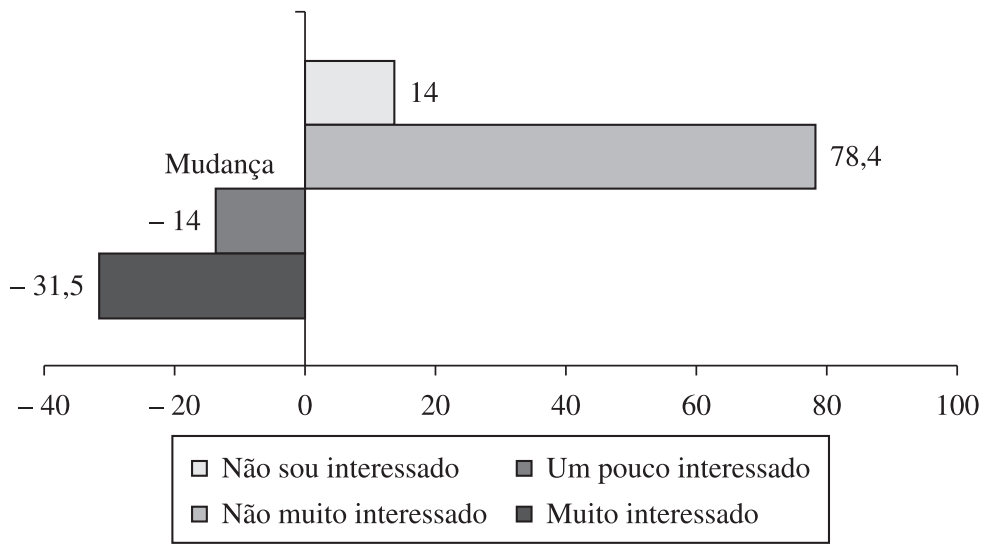

Figura 1. Alteração no interesse pela política em relação a 1990, Brasil, 2005. 


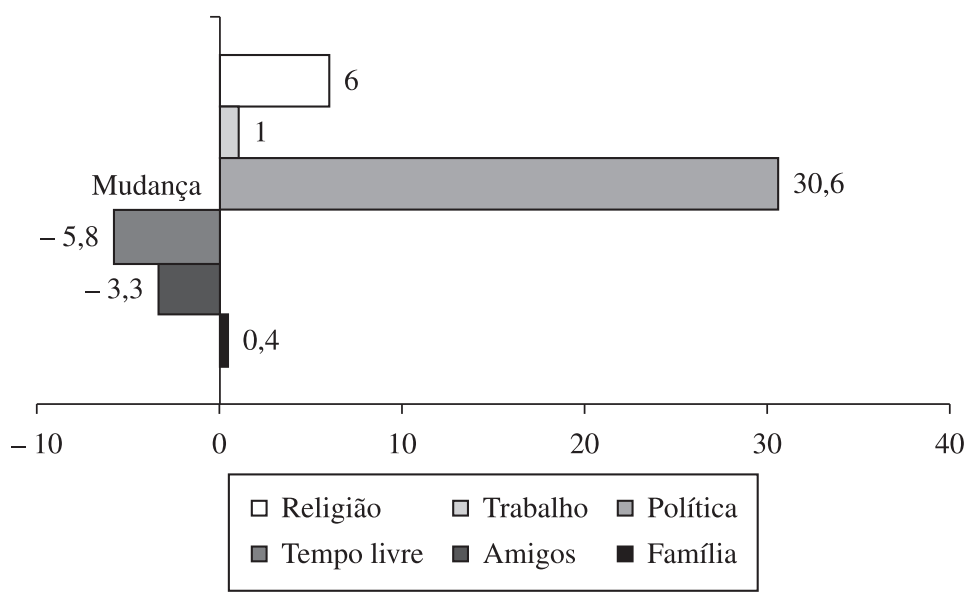

Figura 2. Alteração na importância das instituições em relação a 1990, Brasil, 2005.

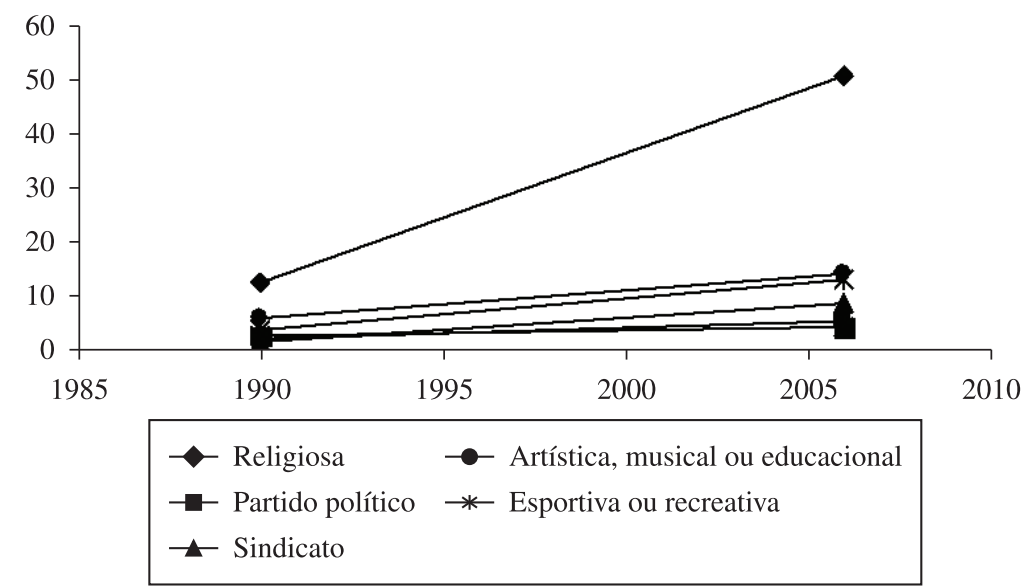

Figura 3. Evolução do pertencimento e participação em instituições, Brasil, 1990/2005.

diminui nos últimos 15 anos: os que se julgam muito interessados e interessados decresceram, já os não muito interessados e não interessados cresceram, principalmente os que se consideram não muito interessado, conforme demonstrado pela Figura $1^{1}$.

Apesar do crescimento do desinteresse pela política, a importância atribuída à política constatou grande crescimento: $30,6 \%$. Este crescimento é bastante elevado se analisarmos as demais instituições avaliadas, conforme verificado na Figura 2 .

A alegação da participação dos indivíduos em instituições formais aumentou ao longo destes anos. Este aumento é estatisticamente relevante ${ }^{2}$. O aumento foi significante tanto em instituições formais,

\footnotetext{
1 Teste qui-quadrado foi igual a o,ooo.

$2 \mathrm{O}$ teste qui-quadrado deu igual a zero em todos os casos.
}

apesar do crescimento baixo da participação em partidos políticos, quanto informais, com destaque à participação religiosa. A Tabela 3 e a Figura 3 demonstram este crescimento, em que se destaca o crescimento de instituições políticas pertencentes à sociedade civil: associações religiosas, culturais, esportivas e humanitárias.

Embora haja um crescimento na participação em instituições sociais, o mesmo não acontece ao focalizar as ações políticas dos cidadãos brasileiros. Não houve mudança na participação dos brasileiros em manifestações ao longo destes 15 anos. Apesar do crescimento das pessoas que já assinaram um abaixo assinado há uma queda significante das que participaram de boicotes. Assim, apesar do aumento da participação em instituições sociais, inclusive em instituições ligadas ao aparato estatal, não há 


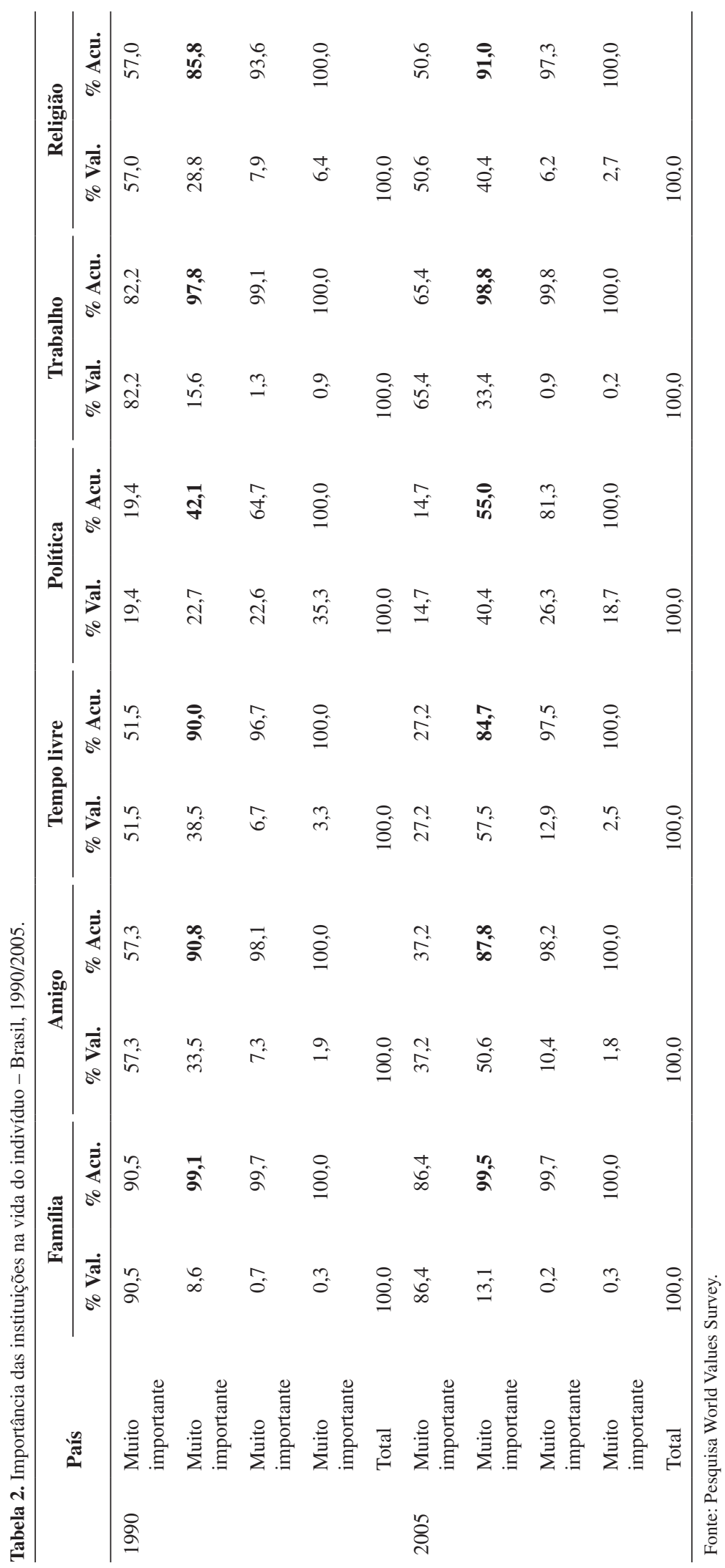


mudanças significantes nas ações políticas e, quando há, há uma queda na participação, como se vê na Tabela 4.

\section{A Apatia com Relação à Participação Política: Análise dos Dados do WVS}

A burocratização do quadro político latino-americano desfavorece uma ampliação na participação política dos seus cidadãos. Esta conjuntura se reflete no cenário político brasileiro, o qual é visto como algo negativo. Recém saído de um processo de redemocratização, com o estabelecimento de instituições democráticas espelhadas na democracia representativa ocidental e o desenvolvimento de uma economia capitalista neoliberal específica, a igualdade política só é observada nas ações eleitorais, mesmo assim podadas nos desajustes do seu sistema eleitoral.

Tabela 3. Pertencimento e participação em instituições, Brasil, 1990/2005.

\begin{tabular}{|c|c|c|c|c|c|c|c|c|c|c|c|c|c|}
\hline & \multirow[t]{2}{*}{ País } & \multicolumn{2}{|c|}{ Religião } & \multicolumn{2}{|c|}{$\begin{array}{l}\text { Partido } \\
\text { político }\end{array}$} & \multicolumn{2}{|c|}{ Sindicatos } & \multicolumn{2}{|c|}{$\begin{array}{c}\text { Associação/ } \\
\text { organização } \\
\text { artística, musical } \\
\text { ou educacional }\end{array}$} & \multicolumn{2}{|c|}{$\begin{array}{l}\text { Associação/ } \\
\text { organização } \\
\text { esportiva ou } \\
\text { recreativa }\end{array}$} & \multicolumn{2}{|c|}{$\begin{array}{c}\text { Associação/ } \\
\text { organização } \\
\text { humanitária } \\
\text { ou de caridade }\end{array}$} \\
\hline & & Freq. & $\%$ & Freq. & $\%$ & Freq. & $\%$ & Freq. & $\%$ & Freq. & $\%$ & Freq. & $\%$ \\
\hline \multirow[t]{4}{*}{1990} & $\begin{array}{l}\text { Não } \\
\text { pertence }\end{array}$ & 1361 & 77,9 & 1668 & 95,5 & 1636 & 93,6 & 1659 & 95,0 & 1605 & 91,9 & 1573 & 90,1 \\
\hline & $\begin{array}{l}\text { Pertence, } \\
\text { mas não } \\
\text { participa }\end{array}$ & 166 & 9,5 & 38 & 2,2 & 83 & 4,7 & 39 & 2,2 & 79 & 4,5 & 66 & 3,8 \\
\hline & $\begin{array}{l}\text { Pertence e } \\
\text { participa }\end{array}$ & 220 & 12,6 & 41 & 2,4 & 28 & 1,6 & 49 & 2,8 & 63 & 3,6 & 108 & 6,2 \\
\hline & Total & 1747 & 100,0 & 1747 & 100,0 & 1747 & 100,0 & 1747 & 100,0 & 1747 & 100,0 & 1747 & 100,0 \\
\hline \multirow[t]{4}{*}{2005} & $\begin{array}{l}\text { Não } \\
\text { pertence }\end{array}$ & 362 & 24,2 & 1331 & 89,7 & 1198 & 80,9 & 1265 & 100,0 & 1196 & 80,5 & 1184 & 80,2 \\
\hline & $\begin{array}{l}\text { Pertence, } \\
\text { mas não } \\
\text { participa }\end{array}$ & 378 & 25,3 & 75 & 5,1 & 152 & 10,3 & 64 & 85,7 & 98 & 6,6 & 86 & 5,8 \\
\hline & $\begin{array}{l}\text { Pertence e } \\
\text { participa }\end{array}$ & 757 & 50,5 & 78 & 5,3 & 131 & 8,9 & 148 & 4,3 & 192 & 12,9 & 207 & 14,0 \\
\hline & Total & 1497 & 100,0 & 1485 & 100,0 & 1481 & 100,0 & 1477 & 10,0 & 1487 & 100,0 & 1477 & 100,0 \\
\hline
\end{tabular}

Fonte: Pesquisa World Values Survey.

Tabela 4. Ações políticas, Brasil, 1990/2005.

\begin{tabular}{|c|c|c|c|c|c|c|c|}
\hline & \multirow[t]{2}{*}{ País } & \multicolumn{2}{|c|}{$\begin{array}{c}\text { Assinar um } \\
\text { abaixo-assinado }\end{array}$} & \multicolumn{2}{|c|}{$\begin{array}{l}\text { Participar de } \\
\text { boicotes }^{2}\end{array}$} & \multicolumn{2}{|c|}{$\begin{array}{c}\text { Participar de manifestações } \\
\text { pacíficas }^{3}\end{array}$} \\
\hline & & Freqüiência & $\%$ & Freqüiência & $\%$ & Frequiência & $\%$ \\
\hline \multirow[t]{4}{*}{1990} & Já fiz & 877 & $\mathbf{5 0 , 8}$ & 176 & 10,5 & 308 & 17,9 \\
\hline & Poderia fazer & 525 & 30,4 & 606 & 36,3 & 690 & 40,1 \\
\hline & Não faria nunca & 324 & 18,8 & 888 & 53,2 & 722 & 42,0 \\
\hline & Total & 1726 & 100,0 & 1670 & 100,0 & 1720 & 100,0 \\
\hline \multirow[t]{4}{*}{2005} & Já fiz & 833 & 55,7 & 117 & 8,0 & 273 & 18,3 \\
\hline & Poderia fazer & 409 & 27,4 & 373 & 25,6 & 594 & 40,0 \\
\hline & Não faria nunca & 253 & 16,9 & 968 & 66,4 & 620 & 41,7 \\
\hline & Total & 1494 & 100,0 & 1458 & 100,0 & 1487 & 100,0 \\
\hline
\end{tabular}

Fonte: Pesquisa World Values Survey. ${ }^{1}$ Qui-quadrado: 0,$021 ;{ }^{2}$ Qui-quadrado: 0,000; ${ }^{3}$ Qui-quadrado: 0,946 
Neste contexto, instituições políticas são consideradas ineficazes, corruptas e assistencialistas. Tal situação cria um fosso entre a sociedade civil e o Estado:

[...] os eleitores parecem mais desconfiados e mais decepcionados com a política - a consequiência parece ter sido a institucionalização de uma apatia generalizada em relação aos meios convencionais da política (partidos, eleições e procedimentos formais, de maneira geral). (Baquero, 2003: 89).

No entanto, a apatia com relação à participação política, principalmente na sua configuração formal e institucionalizada, não é um fenômeno exclusivo brasileiro ou latino-americano. A apatia é um processo mais amplo. Países ocidentais industrializados e considerados democraticamente mais estáveis e maduros tendem a também possuir cidadãos apáticos. Porém, essa análise está restrita a inferências macro na participação política. A teoria democrática liberal prega que as atividades instrumentais do voto são os níveis ideais de participação democrática (Schumpeter, 1994: 321), porém pouco se discute sobre canais alternativos à participação.

Assim, um estudo comparado da participação política se faz necessário. Selecionou-se, pois, dois países considerados democracias estáveis para se comparar ao Brasil: França e EUA. A primeira análise enfoca os dados referentes ao interesse do cidadão pela política.
Segundo a Tabela 5, quase metade dos brasileiros afirmam-se interessado por política e a lhe atribui importância na sua vida.

Ao agregarem-se os valores "muito interessado" com "um pouco interessado", nota-se que o interesse em relação à política é alto, 48,6\%, quando o comparamos ao interesse dos cidadãos franceses (ver Tabela 5 e Figura 4). No entanto, o interesse dos norte-americanos é majoritário, mais freqüente do que dos brasileiros.

Outro dado interessante é o número de indivíduos muito interessados pela política. Com exceção dos norte-americanos, tanto os brasileiros quanto os franceses são muito mais não interessados pela política, do que muito interessado. Tal dado nos leva a concluir que os indivíduos nestes dois últimos países não consideram a política uma instituição que lhe desperta grande interesse.

Para melhor entender tais dados, faz-se necessário analisar a variável da importância da política na vida destes indivíduos. A Tabela 6 e a Figura 4 nos demonstram a importância apresentada a algumas instituições sociais, entre elas a política. Nesta tabela se constata, que das instituições propostas no questionário, a política é que apresenta a menor importância. Ao agregarem-se os valores "muito interessado" com "um pouco interessado", nota-se que o interesse em relação à política é alto, 48,6\%, quando o comparamos ao interesse dos cidadãos franceses, conforme pode-se ver na Tabela 5.

Tabela 5. Interesse pela política, Brasil, França e EUA, 2005.

\begin{tabular}{|c|c|c|c|c|c|c|}
\hline País & & & Freqüiência & Percentual & Porcentagem válida & Percentual acumulado \\
\hline \multirow[t]{5}{*}{ Brasil } & Válido & Muito interessado & 174 & 11,6 & 11,8 & 11,8 \\
\hline & & Um pouco interessado & 543 & 36,2 & 36,8 & 48,6 \\
\hline & & Não muito interessado & 389 & 25,9 & 26,4 & 75,0 \\
\hline & & Não sou interessado & 368 & 24,5 & 25,0 & 100,0 \\
\hline & & Total & 1474 & 98,3 & 100,0 & \\
\hline \multirow[t]{5}{*}{ França } & Válido & Muito interessado & 89 & 8,9 & 8,9 & 8,9 \\
\hline & & Um pouco interessado & 280 & 28,0 & 28,0 & 36,9 \\
\hline & & Não muito interessado & 317 & 31,7 & 31,7 & 68,6 \\
\hline & & Não sou interessado & 314 & 31,4 & 31,4 & 100,0 \\
\hline & & Total & 1000 & 99,9 & 100,0 & \\
\hline \multirow[t]{5}{*}{ EUA } & Válido & Muito interessado & 194 & 15,5 & 15,8 & 15,8 \\
\hline & & Um pouco interessado & 556 & 44,5 & 45,4 & 61,2 \\
\hline & & Não muito interessado & 317 & 25,4 & 25,9 & 87,1 \\
\hline & & Não sou interessado & 158 & 12,7 & 12,9 & 100,0 \\
\hline & & Total & 1225 & 98,1 & 100,0 & \\
\hline
\end{tabular}

Fonte: Pesquisa World Values Survey. 


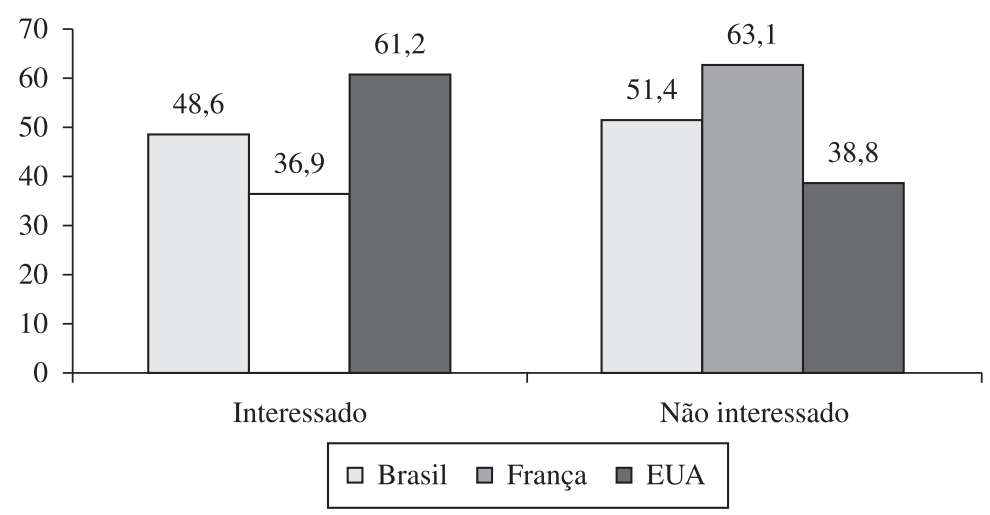

Figura 4. Interesse por política, Brasil, França e EUA, 2005.

Tabela 6. Importância das instituições na vida do indivíduo - Brasil, 2005.

\begin{tabular}{lcccc}
\hline & Muito importante & Importante & Pouco importante & Não é importante \\
\hline Família & 86,4 & 13,1 & 0,2 & 0,3 \\
Amigos & 37,2 & 50,6 & 10,4 & 1,8 \\
Política & 14,7 & 40,4 & 18,7 & 18,7 \\
Trabalho & 65,4 & 33,4 & 0,9 & 0,2 \\
Religião & 50,6 & 40,4 & 6,2 & 2,7 \\
\hline
\end{tabular}

Fonte: Pesquisa World Values Survey.

A baixa importância referente à política não é observada somente nos indivíduos brasileiros. A Tabela 5 e as Figuras 4, 5 e 6 permitem verificar a importância da política na vida dos cidadãos brasileiros, franceses e norte-americanos. Apesar de muito próximos, a importância que o brasileiro atribui à política é maior do que nestes dois outros países.

Verificado o grau de importância e de interesse atribuídos à política nestes países, partimos para a importância atribuída pela população destes países a um governo democrático (Tabela 7). Esta importância varia de 1 a 10, em que 1 significa que não é importante viver em um país governado democraticamente e 10 significa que é muito importante viver em um país governado democraticamente. As populações dos três países consideram importante viver em um país com governo democrático (média acima de 5 ). $\mathrm{O}$ cidadão brasileiro, apesar de próximo ao francês e ao norteamericano, atribui uma importância, estaticamente menor $^{3}$, ao sistema democrático.

3 Teste estatístico ANOVA ( $\mathrm{F}=7,866 ; \mathrm{p}<0,000)$.
Mesmo considerando relativamente importante viver em um país governado democraticamente, na arena política as ações dos cidadãos são pouco freqüentes. A Tabela 8 nos remete a uma análise do pertencimento e da participação dos cidadãos destes três países em suas instâncias coletivas diversas.

Como se pode ver nas Tabelas 8 e 9, há pouca participação nas instituições formais ${ }^{4}$. A participação é ainda menor ao associá-la às instituições relacionadas à sociedade política, como sindicatos e partidos políticos. Com exceção dos 17,9\% norte-americanos participantes em partidos políticos, número esse ainda muito baixo, a participação nestas instituições não ultrapassam os $8,7 \%$ dos brasileiros que participam de sindicatos. A participação é sensivelmente maior em instituições não formais. Entretanto mesmo neste contexto não formal, ela é baixa, chegando a no máximo $22,3 \%$ da população no caso francês.

Apesar da baixa participação em instituições sociais, os cidadãos brasileiros praticaram ações

\footnotetext{
${ }^{4}$ Instituições religiosas não serão analisadas neste trabalho, tanto pelo seu grande caráter divergente entre as demais instituições, quanto dentre dos países. Para sua análise se deve levar em conta o caráter mais secular ou mais tradicional do país em questão (Inglehart, 2004).
} 


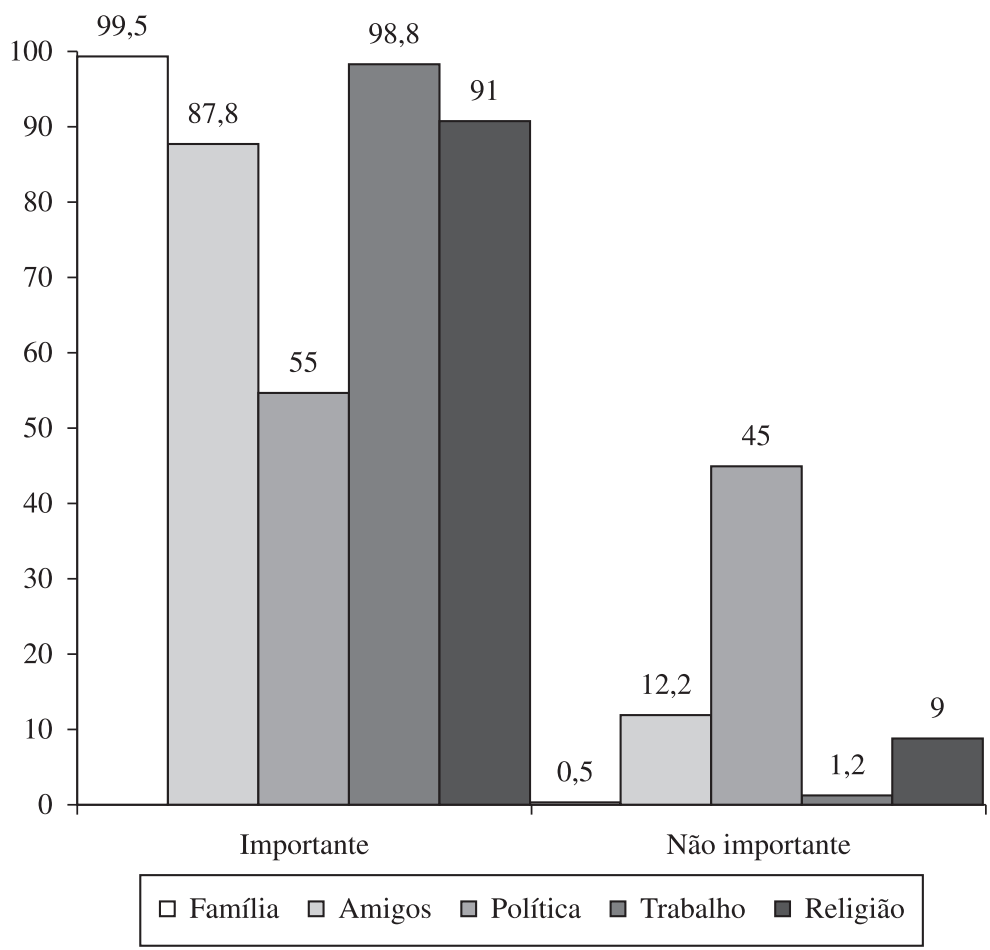

Figura 5. Importância e não importância das instituições - Brasil, 2005.

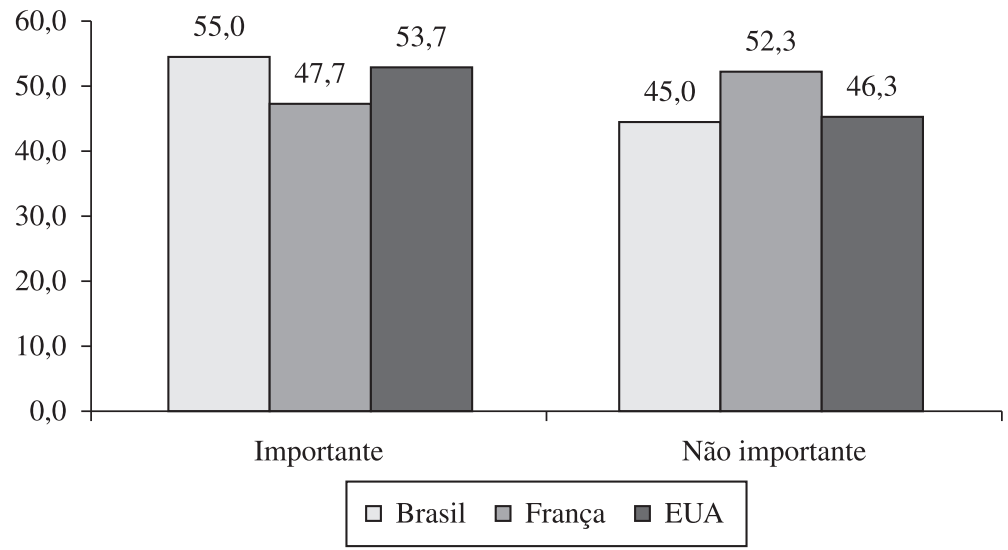

Figura 6. Importância da política - Brasil, França e EUA, 2005.

políticas: 74,6\% já assinaram um abaixo assinado, $64,9 \%$ já participaram de boicotes e $62,4 \%$ já participaram de manifestações pacíficas. A diferença é intensa em relação ao EUA e a França. Com exceção dos $67 \%$ de norte-americanos e dos $46,6 \%$ dos franceses que assinaram ultimamente um abaixo assinado, ela não passa de $21 \%$ de participação ativa, chegando aos ínferos $8,3 \%$ de franceses que participaram de boicotes.
A Tabela 10 nos remete a uma análise da confiança dos cidadãos em suas instituições.

Ao analisar a confiança dos cidadãos nos três países analisados, nota-se também uma baixa confiança nas instituições relacionadas à sociedade política: partidos políticos, sindicatos. A confiança tende a ser maior no caso brasileiro, no qual a participação também tendeu a ser maior. A análise das instituições relacionadas à sociedade civil também corrobora com a afirmação do capital social em relação à confiança e à participação: 
os indivíduos confiam mais nas instituições não ligadas ao aparato estatal, as quais possuem também maiores índices de participação.
Desta forma, a apatia política do brasileiro é um fenômeno real: apesar de atribuir relativa importância à política na sua vida, o brasileiro pouco participa

Tabela 7. Importância de viver em um país governado democraticamente, Brasil, França e EUA, 2005.

\begin{tabular}{|c|c|c|c|}
\hline País & $\mathbf{N}$ & Média & Desvio padrão \\
\hline Brasil & 1451 & 6,19 & 2,586 \\
\hline França & 985 & 6,57 & 2,066 \\
\hline EUA & 1193 & 6,39 & 2,276 \\
\hline Total & 3629 & 6,36 & 2,357 \\
\hline \multicolumn{4}{|c|}{ Student-Newman-Keuls } \\
\hline País & $\mathbf{N}$ & \multicolumn{2}{|c|}{ Subset for alpha $=.05$} \\
\hline & 1 & 2 & 1 \\
\hline Brasil & 1451 & 6,19 & \\
\hline França & 1193 & & 6,39 \\
\hline EUA & 985 & & 6,57 \\
\hline Sig. & & 1,000 & 0,072 \\
\hline
\end{tabular}

Fonte: Pesquisa World Values Survey.

Tabela 8. Pertencimento e participação coletiva, Brasil, França e EUA, 2005.

\begin{tabular}{|c|c|c|c|c|c|c|c|c|c|c|c|c|c|}
\hline & \multirow[t]{2}{*}{ País } & \multicolumn{2}{|c|}{ Religião } & \multicolumn{2}{|c|}{$\begin{array}{l}\text { Partido } \\
\text { político }\end{array}$} & \multicolumn{2}{|c|}{ Sindicatos } & \multicolumn{2}{|c|}{$\begin{array}{c}\text { Associação/ } \\
\text { organização } \\
\text { artística, musical } \\
\text { ou educacional }\end{array}$} & \multicolumn{2}{|c|}{$\begin{array}{c}\text { Associação/ } \\
\text { organização } \\
\text { esportiva ou } \\
\text { recreativa }\end{array}$} & \multicolumn{2}{|c|}{$\begin{array}{c}\text { Associação/ } \\
\text { organização } \\
\text { humanitária } \\
\text { ou de caridade }\end{array}$} \\
\hline & & Freq. & $\%$ & Freq. & $\%$ & Freq. & $\%$ & Freq. & $\%$ & Freq. & $\%$ & Freq. & $\%$ \\
\hline \multirow[t]{4}{*}{ Brasil } & $\begin{array}{l}\text { Pertence e } \\
\text { participa }\end{array}$ & 772 & 51,6 & 78 & 5,3 & 129 & 8,7 & 148 & 10,2 & 183 & 12,3 & 210 & 14,2 \\
\hline & $\begin{array}{l}\text { Pertence, mas } \\
\text { não participa }\end{array}$ & 374 & 25,0 & 74 & 5,0 & 151 & 10,2 & 64 & 4,3 & 96 & 6,5 & 86 & 5,8 \\
\hline & Não pertence & 351 & 23,4 & 1332 & 898 & 1201 & 811 & 1265 & 85,4 & 1207 & 81,2 & 1181 & 80 \\
\hline & Total & 1497 & 100,0 & 1484 & 100,0 & 1481 & 100,0 & 1477 & 100,0 & & 100,0 & 1477 & 100,0 \\
\hline \multirow[t]{4}{*}{ França } & $\begin{array}{l}\text { Pertence e } \\
\text { participa }\end{array}$ & 45 & 4,5 & 26 & 2,6 & 56 & 5,6 & 112 & 11,2 & 223 & 22,3 & 91 & 9,1 \\
\hline & $\begin{array}{l}\text { Pertence, mas } \\
\text { não participa }\end{array}$ & 55 & 5,5 & 32 & 3,2 & 52 & 5,2 & 71 & 7,1 & 81 & 8,1 & 117 & 11,7 \\
\hline & Não pertence & 896 & 90,0 & 942 & 94,2 & 885 & 89,1 & 818 & 81,7 & 694 & 69,5 & 792 & 79,2 \\
\hline & Total & 996 & 100,0 & 1000 & 100,0 & 993 & 100,0 & 1001 & 100,0 & 998 & 100,0 & 1000 & 100,0 \\
\hline \multirow[t]{4}{*}{ EUA } & $\begin{array}{l}\text { Pertence e } \\
\text { participa }\end{array}$ & 423 & 37,6 & 221 & 17,9 & 93 & 7,6 & 177 & 14,4 & 884 & 16,2 & 198 & 16,3 \\
\hline & $\begin{array}{l}\text { Pertence, mas } \\
\text { não participa }\end{array}$ & 349 & 28,2 & 411 & 33,4 & 109 & 8,9 & 149 & 12,1 & 147 & 12,0 & 170 & 14,0 \\
\hline & Não pertence & 466 & 34,2 & 600 & 48,7 & 1026 & 82,1 & 901 & 73,4 & 199 & 71,9 & 847 & 69,7 \\
\hline & Total & 1238 & 100,0 & 1232 & 100,0 & 1228 & 100,0 & 1227 & 100,0 & 1230 & 100,0 & 1215 & 100,0 \\
\hline
\end{tabular}

Fonte: Pesquisa World Values Survey. 
Tabela 9. Ação Política, Brasil, França e EUA, 2005.

\begin{tabular}{|c|c|c|c|c|c|c|c|}
\hline \multirow{2}{*}{\multicolumn{2}{|c|}{ País }} & \multicolumn{2}{|c|}{$\begin{array}{c}\text { Assinar um } \\
\text { abaixo-assinado }\end{array}$} & \multicolumn{2}{|c|}{$\begin{array}{l}\text { Participar de } \\
\text { boicotes }\end{array}$} & \multicolumn{2}{|c|}{$\begin{array}{c}\text { Participar de manifestações } \\
\text { pacíficas }\end{array}$} \\
\hline & & Freqüiência & $\%$ & Freqüiência & $\%$ & Freqüiência & $\%$ \\
\hline \multirow[t]{3}{*}{ Brasil } & Sim & 615 & 74,6 & 74 & 64,9 & 169 & 62,4 \\
\hline & Não & 209 & 25,4 & 40 & 35,1 & 102 & 37,6 \\
\hline & Total & 824 & 100,0 & 114 & 100,0 & 271 & 100,0 \\
\hline \multirow[t]{3}{*}{ França } & Sim & 461 & 46,6 & 83 & 8,3 & 206 & 20,6 \\
\hline & Não & 529 & 53,4 & 917 & 91,7 & 793 & 79,4 \\
\hline & Total & 990 & 100,0 & 1000 & 100,0 & 999 & 100,0 \\
\hline \multirow[t]{3}{*}{ EUA } & Sim & 815 & 67,0 & 247 & 20,4 & 132 & 10,9 \\
\hline & Não & 401 & 33,0 & 964 & 79,6 & 1075 & 89,1 \\
\hline & Total & 1216 & 100,0 & 1211 & 100,0 & 1207 & 100,0 \\
\hline
\end{tabular}

Fonte: Pesquisa World Values Survey.

Tabela 10. Confiança nas instituições, Brasil, França e EUA, 2005.

\begin{tabular}{|c|c|c|c|c|c|c|c|c|c|}
\hline & País & & & Sin & atos & $\begin{array}{c}\text { Orgar } \\
\text { meio }\end{array}$ & $\begin{array}{l}\text { ção de } \\
\text { piente }\end{array}$ & $\begin{array}{r}\text { Organiza } \\
\text { ou }\end{array}$ & $\begin{array}{l}\text { nanitárias } \\
\text { ade }\end{array}$ \\
\hline & & Freq. & $\%$ & Freq. & $\%$ & Freq. & $\%$ & Freq. & $\%$ \\
\hline Brasil & Confia & 317 & 21,3 & 679 & 45,9 & 670 & 68,2 & 991 & 67,2 \\
\hline & Não confia & 1168 & 78,7 & 799 & 54,1 & 800 & 31,8 & 484 & 32,8 \\
\hline & Total & 1485 & 100,0 & 1478 & 100,0 & 1470 & 100,0 & 1475 & 100,0 \\
\hline França & Confia & 162 & 16,4 & 381 & 38,8 & 639 & 64,8 & 658 & 66,2 \\
\hline & Não confia & 828 & 83,6 & 600 & 61,2 & 347 & 35,2 & 336 & 33,8 \\
\hline & Total & 990 & 100,0 & 981 & 100,0 & 986 & 100,0 & 994 & 100,0 \\
\hline EUA & Confia & 186 & 15,4 & 351 & 29,2 & 636 & 52,5 & 768 & 63,7 \\
\hline & Não confia & 1023 & 84,6 & 852 & 70,8 & 848 & 47,5 & 437 & 36,3 \\
\hline & Total & 1209 & 100,0 & 1203 & 100,0 & 1211 & 100,0 & 1205 & 100,0 \\
\hline
\end{tabular}

Fonte: Pesquisa World Values Survey.

das instituições sociais. Esta participação é ainda menor ao se analisar instituições ligadas ao aparato estatal. No entanto, mesmo a participação em canais participativos relacionados à sociedade civil.

A confiança nas instituições também é baixa. Concluiu-se, por fim, que tanto a participação quanto a confiança são maiores nas instituições não relacionadas à sociedade política. Os cidadãos brasileiros tendem a confiar menos em instituições ligadas ao aparato estatal.

No entanto, a apatia em relação à participação política no Brasil é inferior aos outros países analisados - França e EUA. As teorias tradicionais de democracia representativa advogam que esta apatia é favorável à democracia. Países que possuem menores índices de participação política são democracias mais maduras e estáveis. A participação política é mais intensa no Brasil do que na França e no EUA, países esses considerados democraticamente mais estáveis e maduros (Dahl, 2005; Schumpeter, 1994; Eckstein, 1996).

As teorias de democracia participativa vêm como uma alternativa a esta democracia liberal representativa e trabalha em favor da superação desta apatia. Tal teoria defende que a apatia política dos cidadãos é uma patologia da ascensão da democracia representativa, pois a participação política é vital ao bom funcionamento da democracia (Avritzer e Santos, 2002: 32). A participação política é um instrumento que legitima e fortalece a própria democracia. 
Uma sociedade participante tende a ser mais coesa (Pateman, 1992).

Por fim, também se verificou que apesar da confiança nas instituições ser baixa, ela é superior em instituições relacionadas com a sociedade civil. Os cidadãos tendem a confiar menos em instituições ligadas ao aparato estatal, a exemplo dos partidos políticos e dos sindicatos. Instituições não formais e não institucionalizadas não só possuem maiores índices de confiança, como também maiores índices de participação.

Deste modo, ao se comparar a importância e o interesse relativo à política com a ação dos cidadãos na arena política, as variáveis relativas à importância e interesse são altas. O pertencimento e a participação em instituições são baixos, assim como a confiança nestas instituições. Este dado é mais crítico ao enfocarmos instituições relacionadas à sociedade política. A análise nos remete a confirmação da apatia com relação à participação política. Esta análise comprova, também, que a apatia não é um fenômeno exclusivo brasileiro ou latino-americano, ela é um fenômeno mais amplo.

\section{Conclusão: As Mudanças na Participação Política no Brasil no Século XXI}

Há uma queda no interesse do brasileiro pela política entre 1990 e 2005 . Apesar desta queda do percentual de cidadãos interessados pela política, a importância atribuída à política constatou crescimento. Ao comparar este crescimento com a importância relativa às demais instituições sociais analisadas - família, amigos, trabalho e religião - este crescimento é bastante elevado (Ver Tabelas 2 e 6 e Figura 5). A participação política dos indivíduos em instituições políticas e sociais também aumentou neste período. $\mathrm{O}$ aumento foi significante tanto em instituições pertencentes à sociedade política quanto à sociedade civil. Estas últimas tiveram crescimento superior àquelas. No entanto, a ação política vai em via contrária ao pertencimento: ou há uma queda na atividade, ou não há mudança significativa.

Desta forma, de acordo com as análises pós-modernas baseadas na concepção de Barnes e Kaase (1979) no que se refere à relação entre o nível de interesse por política e a atuação em ações políticas como um indicador de envolvimento político, os brasileiros caminham para um quadro de apatia política: queda no interesse do indivíduo por política como também em algumas ações políticas. No entanto, o alto interesse brasileiro por política como também sua ação política maior em relação ao EUA e à França não corrobora os estudos pós-materilistas da teoria do desenvolvimento humano que defendem que países ocidentais desenvolvidos constatam o envolvimento político através do ativismo instrumental e países em desenvolvimento prevalecem a apatia política e o ativismo expressivo.

Outra constatação importante é a ocorrência de mudanças nos canais de participação política. Os cidadãos estão tendendo a participar mais de canais não relacionados à sociedade política. Esta mudança cresceu ao longo dos últimos 15 anos: o crescimento de indivíduos que pertencem e participam de instituições não relacionadas ao aparato estatal é superior àqueles relativos a instituições formais. Essa análise aliada à queda do interesse dos brasileiros pela política e à estagnação nas atividades políticas comprova o crescimento da desconfiança e decepção dos cidadãos brasileiros na arena política. Não se pode considerar o brasileiro apático politicamente, e sim, há uma tendência desses indivíduos em não confiar em instituições ligadas ao aparelho do Estado, como também uma tendência a não legitimar a participação política através de mecanismos formais e institucionalizados. Assim, não só se comprova que o brasileiro não é apático politicamente, como também ratifica o crescimento da desconfiança e decepção dos brasileiros nas instituições sociais ligadas ao aparato estatal. Tal afirmação é corroborada pelo estudo da confiança do brasileiro nas instituições. Instituições relacionadas à sociedade política possuem baixos índices de confiança ao compará-las com as relacionadas à sociedade civil. Destarte, a participação política do brasileiro é exercida primordialmente através de instituições desvinculadas da sociedade política, assim também como suas ações políticas buscam mecanismos também desvinculados do aparato estatal.

Assim sendo, as mudanças encontradas na forma de participação do brasileiro destacam que a participação política exercida primordialmente através do canal eleitoral não é capaz de legitimar o sistema político brasileiro. A baixa participação e desconfiança em instituições ligadas à sociedade política corrobora que a maioria dos brasileiros não se considera membros da sociedade política. A população brasileira não é apática. Ela participa da arena política, no entanto para tal participação ela prioriza instituições não ligadas ao aparato estatal e ações não inseridas nos contextos institucionais do Estado. Assim, o sistema político democrático brasileiro se fortaleceria com uma maior ampliação da participação política dos seus cidadãos, já a participação é um instrumento que proporciona novas perspectivas ao governo, favorece 
um maior entendimento e aceitação das medidas políticas tomadas legitimamente, além de despertar os indivíduos a participarem mais dos assuntos públicos.

\section{Referências}

Avelar, Lúcia. 2007. Participação Política. In: L. Avelar e A. Cintra (orgs.), O Sistema Político Brasileiro: uma introdução. Rio de Janeiro: Fundação Konrad Adenauer, p. 261-280.

Avritzer, Leonardo e Santos, Boaventura Souza. 2002. Para ampliar o cânone democrático. In: B. Santos, Democratizar a Democracia: Os Caminhos Da Democracia Participativa. Rio de Janeiro: Civilização Brasileira, p. 39-82.

Baquero, Marcelo. 2003. Construindo uma outra sociedade: o papel do capital social na estruturação da política participativa no Brasil. Revista de Sociologia e Política, 21: 55-68.

Barnes, Samuel e Kaase, Max. 1979. Political Action: Mass Participation in Five Western Democracies. Beverley Hills and London: Sage Publications.

Chang, Ha-Joon. 2004. Chutando a Escada. São Paulo: Editora Unesp.

Dahl, Robert. 2005. Poliarquia: Participação $e$ Oposição. São Paulo: EdUSP.

Eckstein, Harry. 1996. Division and Cohesion in Democracy: a study of norway. Princeton: Princeton University Press.
Inglehart, Ronald. 1990. Culture shift in advanced industrial society. Princeton: Princeton University Press.

Inglehart, Ronald. 1999. Postmodernization, authority, and democracy. In: P. Norris (org.), Democratic Phoenix: political activism worldwide. Cambridge: Cambridge University Press.

Inglehart, Ronald. 2001. Modernización y posmodernización: el cambio cultural, económico y político en 43 sociedades. Madrid: Centro de Investigaciones Sociológicas, Siglo Veintiuno.

Inglehart, Ronald. 2004. Sacred and Secular: Religion and Politics Worldwide. Cambridge University Press.

Inglehart, Ronald e Welzel, Cristian. 2005. Modernization, cultural change, and democracy: the human development sequence. New York: Cambridge University Press.

Kligemann, Hans-Dieter e Fuchs, Dieter. 1995. Citizens and the State. New York: Oxford University Press.

Norris, Pippa. 2002. Democratic Phoenix: political activism worldwide. Cambridge: Cambridge University Press. http://dx.doi.org/10.1017/ CBO9780511610073

Pateman, Carole. 1992. Participação e Teoria Democrática. Rio de janeiro: Paz e Terra.

Ribeiro, Ednaldo e Borba, Julian. 2010. Participação e Pós-Materialismo na América Latina. Opinião Pública, 16(1): 28-62. http://dx.doi.org/10.1590/ S0104-62762010000100002

Schumpeter, Joseph. 1994. Capitalismo, Socialismo e Democracia. Rio de Janeiro: Zahar. 